\title{
Switchgrass: Your Next Home Heating Fuel?
}

With oil and natural gas prices spiraling ever higher (can everyone say "Peak Oil"?), serious efforts are now underway to find alternative ways to produce energy for homes and businesses. Plant biomass (leaves, stems, and other aboveground material) is one of the potential energy sources that researchers are studying, and standing tall within the realm of biomass sources are the prairie grasses, especially switchgrass (Panicum virgatum).

As a prairie burner, I am not surprised that scientists and investors are following this line of inquiry. Anyone who has ever been out on a prescribed prairie burn will tell you that things get pretty hot when the dry, tall grasses catch on fire, and the more discerning prairie burner will tell you that burning switchgrass produces the hottest, most intense prairie fires of all.

Thus far, researchers have determined that switchgrass can be used in several ways to produce energy: as raw material to fuel boilers for electricity (often as not mixed with coal) or to produce ethanol, and as biofuel pellets for burning in gasifier pellet stoves designed for residential use. Besides being available in these different delivery systems, switchgrass also produces very low carbon dioxide and other chemical emissions when it is burned. It also stores hundreds of tons of carbon in the soil and prevents soil erosion because it is a deep-rooted, perennial plant. Unlike corn, the current main source for ethanol, it requires little in the way of petroleum-based products for its growth and processing. For example, switchgrass can be converted to ethanol by burning the lignin it produces in the ethanol extraction process, while turning corn into ethanol requires the use of gasoline or natural gas. When harvested for its biomass, the switchgrass stubble provides suitable habitat for grassland birds that prefer short- to mediumheight vegetation. Switchgrass truly is a plant with potential, which is why researchers in North America are focusing their attention on it as the model biomass energy crop.

Roger Samson, energy expert and executive director of Resource Efficient Agricultural Production-Canada near Montreal, is so excited about the promise of switchgrass that he suggests planting 150 million acres in North America with this native prairie grass. Samson calculates that doing so would help reduce the need for imported oil, would lower government subsidies to the agriculture and energy sectors, rehabilitate prairie soils and wildlife, provide income opportunities to farmers and entrepreneurs, and reduce carbon dioxide emissions. Samson is not alone. David Bransby, a professor of agronomy and soils at
Auburn University and a recognized expert on biofuels, says that while biofuels won't solve all our energy needs, he expects that agricultural sources, including biomass, will provide as much as 35 percent of the United States' energy supply by 2025. Other researchers, like those involved in the U.S. Department of Energy's Oak Ridge National Laboratory Biofuels Feedstock Development Program, the Northern Great Plains Research Laboratory and the Alliant Energy/Chariton Valley Biomass Project, are doing the serious work needed to make commercially grown switchgrass a viable energy source for the public and a reliable source of income for farmers and other landowners.

Most researchers and economic analysts point to the use of marginal farmland, like those acres currently enrolled in the Conservation Reserve Program, as the place to start planting switchgrass for biomass fuel. The lower cost of using such lands should, they argue, make it economically attractive to the agricultural community and investors. However, they also suggest that there may be opportunities to rotate conventional crops with biomass crops on better lands; if so, both economic returns and maintaining a better soil and wildlife base could be brought into balance. Ecologists, including Michael Palmer at Oklahoma State in a recent letter in Science, are suggesting that biomass plantings could include other native prairie grasses and leguminous forbs instead of being switchgrass monocultures. Testing the effectiveness of such plantings for forage and biofuel is underway in Minnesota, under cooperative efforts by the University of Minnesota, the Land Stewardship Project, and local farmers.

In looking into this biofuel issue, I also came across some researchers who were proposing the use of invasive grasses, including reed canarygrass (Phalaris arundinacea), bahiagrass (Paspalum notatum), and Bermudagrass (Cynodon dactylon). While I think we are fortunate that the federal government has identified switchgrass as the best grass for biomass conversion, and researchers have found that reed canarygrass has physical properties that make it more difficult to process than switchgrass, this is an issue to watch and voice our concern, if necessary.

I hope this global need to move away from fossil fuels and into a biofuel era will help restore or, at least, rehabilitate parts of the North American prairie system as well as impoverished grasslands and their inhabitants throughout the world.

Dave Egan 